\title{
Discussion on Aviation City Culture Construction
}

\author{
Hongsi Yang \\ Zhengzhou Railway Vocational \& Technical College, Zhengzhou 450000, China \\ tuke126@126.com
}

Keywords: aviation city; culture; and construction.

\begin{abstract}
Culture play a more important role in communication and Coexistence of fusion and has become a significant part of a country's soft power affecting a country's international image and state deeply and widely. Airline city culture general can be seen the miniature of a country reflecting the material and spirit creation for people living in the area of city and is the overall impression from the group of city people and city style and features. Airports in their pivotal role increasingly obvious, at the same time also will drive around and even the entire region's economic development, promote the construction of infrastructure and cultural facilities, eventually forming airport as the core of metropolis.
\end{abstract}

\section{Introduction}

As a very broad concept, culture usually have different definition in different areas. But in general, culture closely related with the social life and spiritual civilization of mankind, is in the process of social and historical development of human material and spiritual wealth [1]. Culture as the result of human creation, holding a subtle influence on the human and the human society, can have on people's behavior guiding role, promoting the development of human society and stability, and the historical accumulation from generation to generation. As the formation of world markets and the arrival of the era of globalization, culture in the communication and integration coexistence more play an irreplaceable role, and gradually become an important part of a nation's soft power, deep and widely affects the international image of the country and its international status [2-4].

\section{Urban Culture}

Urban culture, often can be seen as the epitome of a country, reflects the life in urban areas of human material and spiritual creation, is the totality of urban population and urban landscape pattern. Also the scholar thinks, the city is not only a kind of cultural form, a cultural entity, but also the embodiment of the culture. Therefore, urban culture has the following characteristics. First, the aggregation. City as a cultural entity is the central where mankind gathers, which is the result from politics, economy, culture developed in certain stage, it is the focus of the material progress and spiritual civilization. The city itself to absorb foreign cultures and thus gathered into one's own characteristics, the richer content of the urban culture is, the stronger for all the citizens of cohesion is. A city's clustering is, as it were, the interaction between city and its people [5-7].

\subsection{Culture diversity}

The composition of urban culture is clearly not a single, from different parts of the population at the same time also brought colorful culture, behavior, language, all kinds of different culture collide with each other, mutual confluence, eventually formed there are both unity and diversity of urban culture. In a sense, it is of diverse culture, has the unique urban culture development direction and motivation. Third, regional. As the saying goes, one party soil to raise a party person, different geographical environment and geographical position and at the same time also affects the style of city culture and development. And the formation of regional not only improved the urban cultural cohesion, but also to the characteristic of urban culture. And the formation of regional not only improved the urban cultural cohesion, but also to the characteristic of urban culture. By the external image of the city and the diversity of urban characteristics of urban culture, generally contain political 
civilization, spiritual civilization and material civilization and like those three areas, covering the history and culture, citizen quality, various eyesores, infrastructure, and many other aspects, has important influence to the development of cities. The cultural construction in city community is gaining more concerns from social fields due to the development of modernization, considered to be the important content of modern urban construction [8].

While the concept of "aviation city", John Kasarda, by the United States, a professor at the University of North Carolina is put forward for the first time. Kasarda, points out that with the advent of the speed economy era, the airport in the business world and function in the field of transportation will continue to increase. This growth will not only greatly improves the core status of the airport as a hub, will also promote the economic development of surrounding areas, promote the construction of infrastructure and cultural facilities, eventually forming airport as the core of metropolis. As a modern city development mode, one of the most distinctive urban form in aviation city also show different characteristics in the process of development, which in turn are divided into different categories. In the following, we will briefly introduce the two categories and characteristics of the aviation city [9].

\subsection{Aviation metropolis influence region division}

In judging the influence of the aviation city, our main basis is international airport radiation scope, the airport area, airport industry value chain network control force and the type of aviation resources gathered four elements. Based on the four elements, aviation city is divided into a world class and regional level two categories, in the development of the above four elements degree has significant different. New York's Kennedy international airport in the United States and in London's Heathrow airport peripheral area, for example, they are not only in promoting the air transport industry and airport industry internationalization and the surrounding new plays a huge impact, but because of the humanized service and rich urban culture to obtain the high international influence and good international reputation, and further to this unique airport culture become a regional representative characteristics of their own culture, even directly indirectly, the output of its cultural value, synchronous dual influence, improve the economic and cultural is the most high-end aviation city form. And regional aviation city, Japan's naira international airport peripheral area, for example, although has certain influence in the region scope, but the internationalization, the industrial chain, transport network, cultural construction and other key elements, or slightly inferior.

\subsection{The number from the airport link resources type division}

Airport relevant resources, just as its name implies is to point to some areas with its economic base and industry advantage and gathered by the airport industry has the close relation of resources. And here the foundation, some regional focus on developing its own unique industry, thus forming an industry leading aviation city as well as there are also some areas associated resources around for the effective integration and utilization, and then become a variety of industries and the coordinated development of resources comprehensive aviation city.Such as the Dutch Amsterdam schiphol airport, in combination with the garment industry, high-tech industry and other industry resources at the same time, will also be representative characteristics in the Netherlands, flower culture as an important element throughout the Airport District construction. To achieve a long-term perspective, economic and cultural development for the integration of existing resources and exploitation for the characteristics of excavation is aviation metropolis keep vigor and vitality of the important factors for a long time, but also an important means of reasonable resource utilization and maximize, deserves further research and discussion.

How can in the fierce competition in the international economic stage and long maintain a good momentum of development in the process of urban construction, laying a solid foundation for the development of below are only a few of them I would like to introduce.

First, future-oriented planning and a long-term decision is important foundation. There is no doubt that Aviation city construction is a long process, and the government as the identity of the decision-maker is particularly important.If the prior to the construction of the airport can play a positive role in guiding and promoting role, extensive research and academic discussions, formulate scientific and effective construction scheme, construction work after will get twice the result with 
half the effort. It is equally important and decision-making insufficiency;Economic development and cultural construction is not aggressive, the process of the early stage of the large amounts of money and manpower is more rich in exchange for long-term and stable returns.

Second, perfect infrastructure and good network access is necessary.Airport core region, including the airfield, service area and living area of infrastructure construction should be listed as priority, these seemingly less visible runway, the apron or terminal internal infrastructure such as restaurant, lounge, is precisely up to whether the airport can obtain good international reputation and status, to provide convenient services and security of the fundamental elements of flight.And clear on the network, including cash flow, human resources and information interaction, respectively affect the airport area range of internal and external communication, personnel allocation and market, which in turn determines the degree of air traffic is convenient, operation efficiency and degree of connecting with the domestic and foreign each big air port. Meanwhile, it also indirectly affect the aviation city radiation range, determine the aviation city is stay on the regional characteristic to the key to the development of international metropolis.

Third, the economic development and cultural construction be short of one cannot.In this paper we mentioned before, many internationally renowned world-class aviation metropolis besides economic hub of transportation and radiation from the core, also undertakes the important function of culture construction.Modern and contemporary, a single mode of economic development has clearly unable to meet the public's consumption psychology and consumption demand, and to realize the efficient development of the aviation city neither to fall convention, nor to become a "copy", in the form of a particular with regional characteristics of unique cultural characteristics of the elements is essential.With the continuous improvement of regional economic development level, the airport's prosperity and social harmony are more closely related to cultural infrastructure, providing a wide range of cultural services and regional cultural characteristics will become a new topic in the development of future aviation metropolis.

And Zhengzhou airport economic comprehensive experimental area as the most dynamic emerging domestic aviation port, has been given great attention to at the beginning of the construction of cultural development, in promoting economic development and construction projects as well as also culture construction to enhance the quite important position.As a matter of fact, Zhengzhou as an important traffic and economic hub, the core of the birthplace of the fluctuation in five thousand cities, with Songcheng culture such as Kaifeng, Luoyang peony culture, Dengfeng Shaolin culture which is very rich cultural heritage and wealth, has a unique advantage in the construction of culture in the aviation port. If the outstanding traditional culture organic in Henan Zhengzhou air port area is skillfully merged into the central plains economic zone construction,it will no doubt that Zhengzhou, Henan economy and even the long-term development of cultural industry can create a good opportunity.

But when we talk about the concrete measures of cultural construction, the first thing to note is the organic combination. Such as building and airport indoor display can be used with characteristic of Songcheng style, peony can become adornment theme for interior design in the terminal, etc., and the vision highlights of Henan local characteristics and cultural symbol, make its natural and subtly.

We should also enhance the application of the multimedia equipment. For instance we can play the classic Henan opera fragment, display the scenery with mountains and rivers and even can learn from the foreign airport, using the smart touch screen and the robot to interact with the passengers who can entertain themselves and feel the charm of the central culture when they are busy to travel.

\section{Conclusion}

Based on the above to conclude, aviation city culture construction is energetic and young and also is a course with tremendous potential development and vivid learning resources. Numerous foreign worldwide airport offer us one by one unique fresh cases to get reference. We can also add the regional character to it when we learn the scientific and reasonable about the foreign airport in order 
to insure the smoothly constructive development and achieve to gain the double fruit of economic and culture.

\section{Acknowledgment}

\section{Fund 1}

Name: study on strategy of Zhengzhou Airport culture construction.

Number: 14B630027.

Department: Henan province education department soft technology study item.

Fund 2

Name: Study about Service in the central plains and the Zhengzhou airport air service personnel training of the construction of the machine.

Department: Hennan province technology department soft technology study item.

Number: 152400410018.

\section{Reference}

[1] Songtao Wang. Discuss on city culture and city culture construction. Vol.15 (2011), p. 56-62.

[2] YunchunCao, YunyunGu, YanrongXi; The current situation and trend of airport economic development. Questions For Economic. Vol.12 (2006), p. 34-35.

[3] China Civil Airport Association, Report on the development of China Civil Airport 2009-2010. Economic exploration. Vol.12 (2006): p. 4-8.

[4] SubingWen. The new idea of setting the factor about enterprise economic benefit system.Statistics and Decision. Vol.3 (1997), p. 14-15.

[5] QinZhang.Construction of civilian Henan by Zhengzhou Airport to build the 15 minutes central culture net by Zhengzhou night newspaper.

[6] FuqiangWang. Do not forget the shang capital culture net for Zhengzhou Airport construction; ShangDuInternet.

[7] Qi Qi.Some thoughts about the planning and development of Zhengzhou Airport region; www.CARNOC.com.

[8] Johnkasarda Greg lindsay Cao yunchun, Aerotropolis- the future lifestyle Henan Science and Technology press. 